кормопроизводства Республики Коми // Кормопро- Уральского отделения Российской академии наук. изводство. 2011. № 9. С. 33-35.

17. Государственная Фармакопея Российской Федерации. XIII, Т. 3. М.: Министерство здравоохранения РФ, 2015. 1294 с.

18. Беликов В.В., Точкова Т.В., Колесник Н.Т. Экспрессный метод анализа флавоноидов в лекарственном растительном сырье // Проблемы стандартизации и контроля качества лекарственных средств: мат-лы докладов всесоюз. конф. Т. 2. М., 1991. C. $15-16$.

19. Михович Ж.Э., Зайнуллина К.С., Рубан Г.А. Биология и экология цветения свербиги восточной (Bunias orientalis L.) в культуре на Европейском Ceверо-Востоке // Известия Коми научного центра 2016. № 2 (26). С. 36-43.

20. Беликов В.В., Точкова Т.В. Реакция комплексообразования в анализе флавоноидов // Мат-лы II всерос. симпоз. по фенольным соединениям. АлмаАта, 1973. С. 168-172.

Работа проведена на экспериментальной базе УНУ «Научная коллекция живых растений» Ботанического сада Института биологии Коми НЦ УрО РАН, рег. номер 507428. Исследования выполнены в рамках государственного задания по теме «Закономерности процессов репродукции ресурсных растений в культуре на европейском СевероВостоке» № AAAA-A17-117122090004-9.

\title{
FLAVONOLS POOL DISTRIBUTION IN THE AERIAL MASS OF THE BUNIAS ORIENTALIS L. IN THE NORTH
}

(C) 2018

\begin{abstract}
Mikhovich Janna Eduardovna, candidate of biological sciences, researcher of Botanical Garden
Punegov Vasiliy Vitalievich, candidate of chemical sciences, senior researcher of Botanical Garden

Zaynullina Klavdiya Stepanovna, candidate of biological sciences, senior researcher of Botanical Garden

Ruban Galina Alexeevna, senior researcher of Botanical Garden

Institute of Biology of Komi Scientific Centre of the Ural Branch of the Russian Academy of Sciences
\end{abstract}

(Syktyvkar, Russian Federation)

Abstract. The paper presents the results of a biochemical study of the aerial overburden mass of the Bunias orientalis L., grown under the conditions of the middle taiga subzone of the Republic of Komi according to the terms of its harvesting. The mass fraction of flavonols during the vegetative period of plants has been determined. It has been established that in mass budding and mass flowering phases in the row-leaves-buds (or flowers) the mass fraction of flavonols increases from $0,25 \%$ to $6,06 \%$ and from 0,6 to $15,43 \%$, respectively. It is shown that when plants migrate to mass flowering, a sharp increase in the content of flavonols in all the above-ground organs of the plant is observed. A particularly large increase in the mass fraction of flavonols has been detected in the flowers of the overbearing of the eastern plants in comparison with the buds. Unconditional maximum of the pool of flavonols is observed in the flowers of the plant $(15,43 \%)$. But, taking into account the fact that the mass fraction of flowers on the generative shoot is no more than $3 \%$, in the technological plan, a promising source of flavonols from the aboveground mass of the studied plant are the leaves and flowers collected during the flowering phase in the Komi Republic in the third decade of June-July.

Keywords: Bunias orientalis; Brassicaceae; biochemical study; content of flavonols; periods of plants vegetation; distribution of plant organs; flowers; buds; stems; leaves; shoot; Komi Republic; middle taiga subzone; cultivation; fodder plants; medicinal plants; honey plants; food plants; longevity in culture.

УДК 581.9

Статья поступила в редакцию 25.01.2018

\section{РАСТИТЕЛЬНОСТЬ ПАМЯТНИКА ПРИРОДЫ «ГУРЬЕВ ОВРАГ» (ШИГОНСКИЙ РАЙОН САМАРСКОЙ ОБЛАСТИ)}

(C) 2018

Новикова Любовь Александровна, доктор биологических наук, доцент, профессор кафедры общей биологии и биохимии

Пензенский государственный университет (г. Пенза, Российская Федерация)

Саксонов Сергей Владимирович, доктор биологических наук, профессор,

временно исполняющий обязанности директора, заведующий лабораторией проблем фиторазнообразия

Васюков Владимир Михайлович, кандидат биологических наук, научный сотрудник лаборатории проблем фиторазнообразия

Горлов Сергей Евгеньевич, аспирант лаборатории проблем фиторазнообразия

Сенатор Степан Александрович, кандидат биологических наук,

старший научный сотрудник лаборатории проблем фиторазнообразия

Институт экологии Волжского бассейна РАН (2. Тольятти, Самарская область, Российская Федерация)

Соловьева Вера Валентиновна, доктор биологических наук,

профессор кафедры биологии, экологии и методики обучения

Самарский государственный соџиально-педагогический университет (2. Самара, Российская Федераџия)

Аннотаиия. Памятник природы регионального значения «Гурьев овраг» расположен в 1 км северозападнее с. Климовка в Шигонском районе Самарской области. Южную и юго-западную часть участка зани- 
мает овраг, устьем открывающийся в Куйбышевское водохранилище. Правый склон оврага более пологий и зарос широколиственным лесом, левый - крутой, сильно эрозированный, известный под названием гора Гусиха. В устье оврага и вдоль коренного берега сформировались оползневые террасы. Описана кальцефитная флора и растительность левого склона Гурьева оврага (гора Гусиха). Всего сделано 5 описаний, из которых одно (№ 14) располагалось в нижней части горы, а четыре других - в верхней (описания № 15-18). Описания сделаны на крутых склонах (угол наклона 40-50) юго-восточной экспозиции. На описываемом участке преобладает петрофитная полукустарничковая растительность с доминированием Artemisia salsoloides (ПП от 1,0 до 30,0\%), Ephedra distachya (ПП от 0 до 30,0\%), Bassia prostrata (ПП от 0 до 15,0\%), Thymus dubjanskyi (ПП от 0 до 15,0\%), Onosma volgensis (от 0 до 15,0\%), Anthemis trotzkiana (от 0 до 5,0\%); реже встречается Linum uralense (от 0 до 1,0\%). Распространение получили сообщества из формации с доминированием Artemisia salsoloides (описания № 14, 16), которые занимают нижние и средние части крутых склонов горы Гусихи и относятся к двум разным ассоциациям. В нижней части склонов развивается юзепчуковокачимово-простертопрутняково-солянковиднопольнная ассоциация [Artemisia salsoloides + Bassia prostrata + Gypsophila juzерсzиkii], а в средней - волжскооносмово-солянковиднопольнная ассоциация [Artemisia salsoloides + Onosma volgensis]. В верхней части крутых склонов развиваются ассоциации из формаций с доминированием других видов полукустарничков: Bassia prostrata, Ephedra distachya и Thymus dubjanskyi (описания № 15, 17 , 18): волосатикоковыльно-солянковиднопольнно-простертопрутняковая [Bassia prostrata + Artemisia salsoloides + Stipa capillata], простертопрутняково-солянковиднопольнно-двуколосковоэфедровая [Ерhеdra distachya + Artemisia salsoloides + Bassia prostrata $]$ и юзепчуковокачимово-корнух-троцкогопупавко-дубянскочабрецовая [Thymus dubjanskyi + Anthemis trotzkiana + Gypsophila јиzерсzukii] ассоциации. В условиях наименьшего эрозионного процесса постепенно в сообщества внедряются разные виды злаков (Stipa capillata), a при усилении эрозионных процессов - представители разнотравья (Gypsophila јuzepczukii) или полукустарничков (Artemisia salsoloides, Anthemis trotzkiana), что способствует возобновлению этих особенно редких для Самарской области видов.

Ключевые слова: растительность; памятник природы «Гурьев овраг»; гора Гусиха; Шигонский район; Самарская область; Средне-Волжский биосферный резерват; Красная книга; Anthemis trotzkiana; Artemisia salsoloides; Gypsophila juzepczukii; Thymus dubjanskyi.

\section{Введение}

Описания растительности Поволжья началось еще в XVIII в. и до сегодняшних дней природа остается мало изученной. Карл Клаус был одним из первых, кто отмечал уникальность флоры меловых гор [1]. Удивительные меловые обнажения Шигонского района являются рефугиумом произрастания многих редких и исчезающих растений, представляющих интерес для природы не только Самарской области, но и России в целом [2]. С целью поддержания экологического равновесия в природе необходимо сохранить существующие степные экосистемы во всем их разнообразии. И особенно в этом нуждаются наиболее уязвимые кальцефитные степи. Экологические проблемы в степных регионах решаются следующим образом: создаются особые охраняемые природные территории; составляются списки исчезающих степных растений и животных для внесения в Красную книгу; принимаются меры для сохранения и восстановления исчезающих видов флоры и фауны; восстанавливаются лесостепные ландшафты, нарушенные в процессе хозяйственной деятельности.

\section{Объект и методика исследования}

Памятник природы регионального значения «Гурьев овраг» расположен в 1 км северо-западнее с. Климовка в Шигонском районе Самарской области. Утвержден решением Куйбышевского облисполкома № 6 от 19.04.1983 г. Площадь участка составляет 177,67 га [3-6]. Урочище, примечательное в ботаническом отношении, располагается на территории Кузькинского лесничества Волжского государственного лесоохотничьего хозяйства (кв. № 70 и 78) в границах Средне-Волжского биосферного резервата.

Южную и юго-западную часть памятника природы занимает овраг, устьем открывающийся в Куйбышевское водохранилище. Овраг представляет собой узкий и глубокий каньон, протянувшийся с запада на восток (длина достигает примерно 3 км, глубина - 50 м). Правый склон более пологий и зарос широколиственным лесом, а левый склон очень крутой и сильно об- наженный, известный под названием гора Гусиха. В устье оврага и вдоль коренного берега сформировались оползневые террасы. Абсолютная высота территории достигает 140 м над уровнем моря. Наблюдается обнажение материнских меловых пород (маастрихтский ярус верхнего мела) [7; 8]. В овраге бьет несколько родников, образующих водоток, который впадает в р. Волгу (Куйбышевское водохранилище).

Наибольшую часть территории занимают вторичные старовозрастные широколиственные леса. На крутых склонах преимущественно южной экспозиции отмечаются фрагменты петрофитных степей, а на более пологих склонах расположены луговые степи. В долине Гурьева оврага, среди разреженных дубрав и березняков, развивается лугово-степное разнотравье.

Основная территория участка используется под выпас, хотя крутосклонье, подверженное интенсивной эрозии, зачастую недоступно для животных.

Согласно «Реестру особо охраняемых природных территорий регионального значения Самарской области» [3], на территории памятника природы запрещается всякая деятельность, влекущая за собой нарушение сохранности памятника природы, в том числе распашка земель и любые агротехнические и лесохозяйственные работы, связанные с нарушением целостности почвенного покрова.

Описание растительных сообществ проводилось по традиционной методике [9-10] с использованием метода доминантной классификации растительности согласно [11-15].

\section{Результаты исследования и их обсуждение}

Нами описана кальцефитная флора и растительность левого склона Гурьева оврага (горы Гусиха). Всего сделано 5 описаний, из которых одно (описание № 14) располагалось в нижней части горы, а четыре других - в верхней (описания № 15-18). Описания сделаны на очень крутых склонах (угол наклона 40-50²) юго-восточной экспозиции. Полные фитоценотические описания приведены в табл. 1. 
Таблица 1 - Фитоценотическая характеристика пробных площадок памятника природы «Гурьев овраг» (2016 г.)

\begin{tabular}{|c|c|c|c|c|c|c|c|c|}
\hline Названия видов & ХБГ & $\Phi \Gamma$ & ЭГ & № 14 & № 15 & № 16 & № 17 & № 18 \\
\hline \multicolumn{9}{|l|}{ Деревья и полукустарнички } \\
\hline Anthemis trotzkiana & П/Кч & $\mathrm{c}$ & K & & 5 & & & \\
\hline Artemisia salsoloides & $\Pi / \kappa ч$ & $\mathrm{c}$ & K & 30 & 1 & 25 & 12 & 20 \\
\hline Asperula exasperata & $\Pi /$ Пч & $\mathrm{c}$ & $\kappa$ & & 1 & & & \\
\hline Bassia prostrata & $\Pi /$ Кч & $\mathrm{c}$ & K & 10 & & & 15 & 5 \\
\hline Ephedra distachya & $\Pi / К ч$ & $\mathrm{c}$ & К & & & & 3 & 30 \\
\hline Linum uralense & $\Pi /$ Кч & $\mathrm{c}$ & $\kappa$ & & 1 & 0,5 & & \\
\hline Onosma volgensis & П/Кч & $\mathrm{c}$ & к & & 1 & 15 & & \\
\hline Thymus dubjanskyi & $\Pi /$ Кч & $\mathrm{c}$ & К & & 15 & 0,5 & & \\
\hline \multicolumn{9}{|l|}{ Злаки и осоки } \\
\hline Helictotrichon desertorum & злак. & $\mathrm{c}$ & MK & 2 & & & & \\
\hline Melica transsilvanica & злак. & $\mathrm{c}$ & МК & 3 & & & & \\
\hline Stipa capillata & злак. & $\mathrm{c}$ & К & 1 & & & 15 & 5 \\
\hline \multicolumn{9}{|l|}{ Бобовые } \\
\hline Coronilla varia & боб. & л & КM & 0,5 & & & & \\
\hline Hedysarum gmelinii & боб. & $\mathrm{c}$ & К & & & 0,5 & 0,5 & 0,5 \\
\hline \multicolumn{9}{|l|}{ Разнотравье } \\
\hline Allium cretaceun & разн. & $\mathrm{c}$ & K & 1 & & 1 & 0,5 & \\
\hline Echinops ruthenicus & разн. & $\mathrm{c}$ & $\kappa$ & 0,5 & & 3 & & \\
\hline Euphorbia seguieriana & разн. & $\mathrm{c}$ & Мк & & 1 & & & \\
\hline Galium ruthenicum & разн. & $\mathrm{c}$ & MK & 0,5 & & & 0,5 & \\
\hline Galatella villosa & разн. & $\mathrm{c}$ & K & & & 0,5 & & \\
\hline Gypsophila juzepczukii & разн. & $\mathrm{c}$ & K & 5 & 7 & & & \\
\hline Gypsophila volgensis & pa3н. & $\mathrm{c}$ & МК & & & & 0,5 & 0,5 \\
\hline Mulgedium tataricum & разн. & л & КМ & 0,5 & & & & \\
\hline Pimpinella titanophila & pa3н. & $\mathrm{c}$ & К & 0,5 & 1 & & & \\
\hline Общее число видов & & & & 12 & 9 & 8 & 8 & 6 \\
\hline ОПП & & & & 54,5 & 33,0 & 46,0 & 47,0 & 61,5 \\
\hline \multicolumn{9}{|c|}{ Соотношение фитоценотических групп } \\
\hline Степные & $\mathrm{c}$ & & & 53,5 & 33,0 & 46,0 & 47,0 & 61,0 \\
\hline Луговые & л & & & 1,0 & 0,0 & 0,0 & 0,0 & \\
\hline \multicolumn{9}{|c|}{ Соотношение экологических групп } \\
\hline ксерофиты & К & & & 48,0 & 32,0 & 46,0 & 46,0 & 61,0 \\
\hline мезоксерофиты & МК & & & 5,5 & 1,0 & 0,0 & 1,0 & 0,5 \\
\hline ксеромезофиы & КМ & & & 1,0 & 0,0 & 0,0 & 0,0 & 0,0 \\
\hline мезофиты & M & & & 0,0 & 0,0 & 0,0 & 0,0 & 0,0 \\
\hline \multicolumn{9}{|c|}{ Соотношение хозяйственно-биологических групп } \\
\hline Деревья и полукустарнички & Дер, п/кч. & & & 40,0 & 24,0 & 41,0 & 30,0 & 55,0 \\
\hline Злаки и осоки & Злак., осок. & & & 6,0 & 0,0 & 0,0 & 15,0 & 5,0 \\
\hline Бобовые и разнотравье & Боб., разн. & & & 8,5 & 9,0 & 5,0 & 2,0 & 1,0 \\
\hline
\end{tabular}

Примечание. ОПП - общее проективное покрытие, \%; ПП - проективное покрытие отдельных видов; ХБГ - хозяйственно-биологические группы: дер. - деревья, $n / \kappa ч-$ полукустарнички; злак. - злаки, осок. - осоки, боб. - бобовые, разн. - разнотравье; ЭГ - экологические группы: $\kappa$ - ксерофиты, мк - мезоксерофиты, км ксеромезофиты, $\boldsymbol{M}$ - мезофиты; ФГ - фитоценотические группы: $c$ - степные виды, $л$ - луговые виды; № 14 юзепчуковокачимово-простертопрутняково-солянковиднополынная полукустарничковая растительность; № 15 - юзепчуковокачимово-корнух-троцкогопупавко-дубянскочабрецовая полукустарничковая растительность; № 16 - волжскооносмово-солянковиднополынная полукустарничковая растительность; № 17 - волосатикоковыльно-солянковиднополынно-простертопрутняковая полукустарничковая растительность; № 18 простертопрутняково-солянковиднополынно-двуколосковоэфедровая полукустарничковая растительность.

На описываемом участке преобладает петрофитная полукустарничковая растительность с доминированием разных видов: Artemisia salsoloides (ПП от 1,0 до 30,0\%), Ephedra distachya (ПП от 0 до 30,0\%), Bassia prostrata (ПП от 0 до 15,0\%), Thymus dubjanskyi (ПП от 0 до 15,0\%), Onosma volgensis (от 0 до 15,0\%), Anthemis trotzkiana (от 0 до 5,0\%), реже встречается Linum uralense (от 0 до 1,0\%).

В нижней и средней частях горы на крутых склонах $\left(40-50^{\circ}\right)$ наибольшее распространение получили сообщества с доминированием Artemisia salsoloides (описания № 14, 16), которые относятся к двум разным ассоциациям.
Первое сообщество юзепчуковокачимово-простертопрутняково-солянковиднопольнной [Artemisia salsoloides + Bassia prostrata + Gypsophila juzepczukii] ассоциации развивается в нижней части склона горы (описание № 14). ОПП составляет 54,5\%. Из явно господствующей группы степных видов особенно хорошо представлены настоящие ксерофиты. Преобладают полукустарнички $(40,0 \%)$, особенно Artemisia salsoloides (30,0\%), в меньшей мере Bassia prostrata $(10,0 \%)$. В сообществе принимают участие бобовые и разнотравье $(8,5 \%)$, злаки $(6,0 \%)$. Из разнотравья выделяется Gypsophila juzepczukii (5,0\%), из злаков - Melica transsilvanica $(3,0 \%)$ и Helicto- 
trichon desertorum (2,0\%). В фитоценозе отмечено 12 видов.

Второе сообщество волюскооносмово-солянковиднополынной [Artemisia salsoloides + Onosma volgensis] ассоциации (описание № 16) располагается выше по склону горы. ОПП - 46,0\%. Оно сложено исключительно степными эуксерофитными видами. Здесь также преобладают полукустарнички $(41,0 \%)$, незначительно участвуют бобовые и разнотравье $(5,0 \%)$, злаки отсутствуют полностью. Из полукустарничков доминируют Artemisia salsoloides $(25,0 \%)$ и Onosma volgensis $(15,0 \%)$, из разнотравья выделяется Echinops ruthenicus (3,0\%). В сообществе зарегистрировано 8 видов растений.

В верхней части горы на менее крутых склонах (30-40) развиваются сообщества с доминированием других видов полукустарничков: Bassia prostrata, Ephedra distachya и Thymus dubjanskyi (описания № $15,17,18)$ в зависимости от разной степени крутизны склонов.

Сначала по склону горы располагается сообщество волосатикоковыльно-солянковиднополыннопростертопрутняковой ассоциации [Bassia prostrata + Artemisia salsoloides + Stipa capillata] (описание № 17). ОПП - 47,0\%. Сообщество сложено исключительно степными видами, из которых большинство составляют эуксерофиты. Также преобладают полукустарнички (30,0\%): Bassia prostrata $(15,0 \%)$ и Artemisia salsoloides (12,0\%), присутствует Ephedra distachya $(3,0 \%)$. В этом сообществе довольно заметны злаки $(15,0 \%)$, которые представлены исключительно Stipa capillata, и совсем незначительны - бобовые и разнотравье $(2,0 \%)$. Здесь отмечено всего 8 видов растений.

Далее следует сообщество простертопрутняково-солянковиднополынно-двуколосковоэфедровой ассоциации [Ephedra distachya + Artemisia salsoloides + Bassia prostrata] (описание № 18). В сообществе отмечается самое высокое ОПП $(61,5 \%)$, причем почти все виды относятся к степным эуксерофитам $(60,0 \%)$. В фитоценозе явно доминируют полукустарнички $(55,0 \%)$, из которых особенно выделяются Ephedra distachya $(30,0 \%)$ и Artemisia salsoloides $(20,0 \%)$, в меньшей степени - Bassia prostrata $(5,0 \%)$. Другие хозяйственно-биологические группы представлены слабо: злаки составляют 5,0\% и представлены только Stipa capillata, а разнотравье едва достигает $1,0 \%$. В сообществе отмечено 6 видов.

Сообщества юзепчуковокачимово-корнух-троцкогопупавко-дубянскочабрецовой ассоциации [Thymus dubjanskyi + Anthemis trotzkiana + Gypsophila juzepczukii] отмечается только в верхней части горы (описание № 15). ОПП - очень низко (33,0\%), причем практически полностью состоит из степных эуксерофитов. По-прежнему доминируют полукустарнички (24,0\%): Thymus dubjanskyi (15,0\%), присутствует Anthemis trotzkiana (5,0\%). Этот очень редкий вид отмечен в составе только одного сообщества. Разнотравье дольно плохо представлено $(9,0 \%)$, в нем особенно выделяется Gypsophila juzepczukii $(7,0 \%)$. В сообществе отмечено 9 видов растений.

\section{Выводы}

В заключение можно сделать следующие выводы о характере распространения фитоценозов основных растительных ассоциаций по территории памятника природы «Гурьев овраг» (Гора Гусиха): по крутым склонам юго-восточной экспозиции $\left(40-50^{\circ}\right)$ в ниж- ней и средней их частях большую площадь занимают сообщества с доминированием Artemisia salsoloides, а в верхней части на менее крутых склонах (30-40) развиваются фитоценозы с доминированием Bassia prostrata, Ephedra distachya и Thymus dubjanskyi.

В условиях наименьшего эрозионного процесса постепенно в сообщества внедряются разные виды злаков (Stipa capillata), а при усилении эрозионных процессов - представители разнотравья (Gypsophila juzepczukii) или полукустарничков (Artemisia salsoloides, Anthemis trotzkiana), что способствует возобновлению этих редких для Самарской области видов [16-20].

\section{Список литературы:}

1. Клаус К. Флоры местные приволжских стран. СПб., 1852.312 c.

2. Калашникова О.В., Плаксина Т.И. Кальцефильная флора меловых обнажений провинции Приволжской возвышенности Самарской области // Известия Самарского научного центра Российской академии наук. 2010. T. 12, № 1 (13). С. 691-695.

3. Каталог государственных памятников природы Куйбышевской области. Куйбышев: Ин-т Волгогипрозем, Куйб. обл. совет ВООП. 1989. 73 с.; 1990. 72 с.

4. Плаксина Т.И., Головин В.И. Гурьев овраг // «Зеленая книга» Поволжья: Охраняемые природные территории Самарской области / сост. А.С. Захаров, М.С. Горелов. Самара: Кн. изд-во, 1995. С. 299-300.

5. Памятники природы Куйбышевской области / сост. В.И. Матвеев, М.С. Горелов. Куйбышев: Кн. изд-во, 1986. 157 с.

6. Реестр особо охраняемых природных территорий регионального значения Самарской области / сост. А.С. Паженков. Самара: Экотон, 2010. 259 с.

7. Захаров А.С. Рельеф Куйбышевской области. Куйбышев, 1971. 86 с.

8. Иванов А.М., Поляков К.В. Геологическое строение Куйбышевской области. Куйбышев: Изд-во Куйбыш. обл. музея краеведения, 1960.81с.

9. Ипатов В.С. Методы описания фитоценоза. СПб.: СПбГУ, 2000. 56 с.

10. Ипатов В.С., Мирин Д.М. Описания фитоценоза. Метод. рекомендации. СПб.: СПбГУ, 2008. 71 с.

11. Новикова Л.А., Леонова Н.А. Меловая растительность Пензенской области на примере памятника природы «Субботинские склоны» // Известия высших учебных заведений. Поволжский регион. Естественные науки. 2014. Вып. 2 (6). С. 46-56.

12. Новикова Л.А., Леонова Н.А., Панькина Д.В., Кулакова Д.А. Кальцефитная растительность Пензенской области как резерват редких и реликтовых растений (памятник природы «Субботинские склоны») // Известия Самарского научного центра РАН. 2014. T. 16, № 1. С. 108-114.

13. Новикова Л.А., Леонова Н.А. Современное состояние кальцефитной растительности Пензенской области // Известия Самарского научного центра PAH. 2014. T. 16, № 5. С. 158-163.

14. Новикова Л.А., Панькина Д.В., Миронова А.А., Кулагина Е.Ю. Редкие растения и растительные сообщества каменисто-песчаных степей Пензенской области (на примере памятников природы «Ардымский шихан» и «Ольшанские склоны») // Известия Самарского научного центра РАН. 2015. Т. 17, № 4 (4). С. 691-698.

15. Новикова Л.А., Панькина Д.В., Миронова А.А., Кулагина Е.Ю. Петрофитный элемент во флоре Пен- 
зенской области (на примере двух урочищ «Большая ендова» и «Малая ендова» // Известия Самарского научного центра РАН. 2016. Т. 18, № 5. С. 112-117.

16. Красная книга Российской Федерации (растения) / гл. редкол. Ю.П. Трутнев и др.; сост.: Р.В. Камелин и др. М.: Т-во научных изданий КМК, 2008. $855 \mathrm{c}$.

17. Красная книга Самарской области. Т. 1. Редкие виды растений, лишайников и грибов / под ред. чл.-кор. Г.С. Розенберга и проф. С.В. Саксонова. Тольятти: ИЭВБ РАН, 2007. 372 с.
18. Плаксина Т.И. Редкие и исчезающие растения Самарской области. Самара: Самарский университет, 1998. 272 c.

19. Плаксина Т.И. Конспект флоры Волго-Уральского региона. Самара: Самарский университет, 2001. $388 \mathrm{c}$.

20. Саксонов С.В., Сенатор С.А. Путеводитель по Самарской флоре (1851-2011). Флора Волжского бассейна. Т. 1. Тольятти: Кассандра, 2012. 511 с.

Работа выполнена при поддержке РФФИ, проeкm № 16-44-630414 p_a.

\section{VEGETATION OF THE NATURAL MONUMENT «GUREV RAVINE» (SHIGONSKY DISTRICT OF THE SAMARA REGION)}

Novikova Lubov Alexandrovna, doctor of biological sciences, professor of General Biology and Biochemistry Department Penza State University (Penza, Russian Federation)

Saksonov Sergey Vladimirovich, doctor of biological sciences, professor, acting director, head of Phytodiversity Problems Laboratory

Vasjukov Vladimir Mikhailovich, candidate of biological sciences, researcher of Phytodiversity Problems Laboratory

Gorlov Sergey Evgenyevich, postgraduate student of Phytodiversity Problems Laboratory

Senator Stepan Aleksandrovich, candidate of biological sciences, senior researcher of Phytodiversity Problems Laboratory

Institute of Ecology of the Volga River Basin of Russian Academy of Sciences

(Togliatti, Samara Region, Russian Federation)

Solovieva Vera Valentinovna, doctor of biological sciences,

professor of Chair of Biology, Ecology and Methods of Teaching

Samara State University of Social Sciences and Education (Samara, Russian Federation)

Abstract. The nature monument of regional value «Gurev ravine» is located $1 \mathrm{~km}$ North-West village Klimovka of Shigonsky District in the Samara Region. The southern and South-Western part is occupied by the ravine, the mouth opening in the Kuibyshev reservoir. The right slope is less steep and is overgrown with deciduous forest, and the left slope is very steep and heavily nude, known as Gusikha mountain. At the mouth of the ravine as well as along the indigenous coast landslide terraces have been formed. We have described calciphyte flora and vegetation of the left slope, «Guriev ravine» (Gusikha mountain). We have made 5 descriptions, one (description № 14) is located at the bottom of this mountain and the other ones are at the top (descriptions № 15-18). All descriptions are made on very steep slopes (angle of $40-50^{\circ}$ ) of South-Eastern exposure. The described area is dominated by subshrub vegetation with dominance of different species: Artemisia salsoloides (from 1,0 to 30,0\%), Ephedra distachya (from 0 to 30,0\%), Bassia prostrata (from 0 to 15,0\%), Thymus dubjanskyi (from 0 to 15,0\%), Onosma volgensis (from 0 to 15,0\%), Anthemis trotzkiana (from 0 to 5,0\%); less common Linum uralense (from 0 to 1,0\%). Artemisia salsoloides (descriptions № 14, 16) occupy the lower and middle parts of the steep slopes of Gusikha mountain. They belong to two different associations. At the bottom of the slopes there are Artemisia salsoloides + Bassia prostrata + Gypsophila juzepczukii, in the middle - Artemisia salsoloides + Onosma volgensis. At the top of steep slopes there are Bassia prostrata, Ephedra distachya and Thymus dubjanskyi (descriptions № 15, 17, 18): Bassia prostrata + Artemisia salsoloides + Stipa capillata, Ephedra distachya + Artemisia salsoloides + Bassia prostrate and Thymus dubjanskyi + Anthemis trotzkiana + Gypsophila juzepczukii Association. Different types of Stipa capillata gradually implemented into the community as well as Gypsophila juzepczukii or Artemisia salsoloides, Anthemis trotzkiana, which contributes to the resumption of these particularly rare for the Samara Region species.

Keywords: vegetation; natural monument «Gurev ravine»; Gusikha mountain; Shigonsky District; Samara Region; Middle Volga biosphere reserve; Red book; Anthemis trotzkiana; Artemisia salsoloides; Gypsophila juzepczukii; Thymus dubjanskyi.

УДК 595.768.12

Статья поступила в редакцию 01.03.2018

\section{ДИНАМИКА ПЛОТНОСТИ ЖУКОВ-ЛИСТОЕДОВ (COLEOPTЕRA, CHRYSOMELIDAE) В АГРОЦЕНОЗАХ ЗЛАКОВЫХ КУЛЬТУР САМАРСКОЙ ОБЛАСТИ}

(C) 2018

Павлов Сергей Иванович, кандидат биологических наук, доцент кафедры биологии, экологии и методики обучения

Яицкий Андрей Степанович, старший преподаватель кафедры биологии, экологии и методики обучения Самарский государственный социально-педагогический университет (г. Самара, Российская Федерация)

Аннотация. В течение 1974-2010 гг. в зоне левобережной лесостепи Поволжья на полях злаковых культур Самарской области, в природных условиях и садках, изучались динамика развития растений озимой и 